\title{
CONSONÂNCIAS E DISSONÂNCIAS Nos Modos DE \\ Escuta Na Música E Na Psicanálise
}

\author{
Olga Picún1 \\ Ana María Fernández Caraballo2
}

\section{RESUMO}

Na ampla história da música ocidental, cujo antecedente direto é geralmente localizado na Grécia Antiga, o ouvinte e a escuta experimentaram múltiplas mudanças. A lei que rege um modo de escutar não se encontra fora de determinações históricas, políticas, sociais que excedem o campo especificamente musical. Não obstante, as transformações musicais são inevitáveis para se aproximar de uma compreensão das mudanças que se produzem no ouvinte e no ato de escutar uma obra musical. De que maneira a música foi tratada por Freud e por Lacan? Qual interesse pode suscitar para a psicanálise as dimensões sonoras em seus diferentes tratamentos? De que modo se produzem as transformações sonoras no modernismo e como elas afetam a escuta? Que relações podem ser estabelecidas entre estas transformações e a psicanálise?

Palavras Chave: Consonâncias; Dissonâncias; Música; Psicanálise.

1 Licenciada em Musicologia, Mestre em Ciências Antropológicas e em Etnomusicologia e Doutora em Ciências Antropológicas. Professora Adjunta do Departamento de Teoria e Metodologia da Faculdade de Informação e Comunicação da Universidad de la República - Udelar (Uruguai). Membro do Sistema Nacional de Investigadores de la Agencia Nacional de Investigación e Innovación (Uruguai). Contato: olga.picun@fic.edu.uy

2 Licenciada em Psicologia e em Linguística, Magistrada em Psicologia e Educação, Doutora pela Universidad Complutense de Madrid, Psicanalista. Diretora do Departamento de Ensino e Aprendizagem do Instituto de Educação, Faculdade de Humanidades e Ciências da Educação da Universidad de la República - Udelar (Uruguai). Contato: amfernandezcaraballo@gmail.com 


\title{
IMPORTÂNCIA DA DimENSÃo SONORA PARA A PSICANÁLISE3
}

\begin{abstract}
A função da música se mostra irredutível a tudo aquilo que seria possível de se traduzir sob a forma verbal. Ela se exerce em baixo da língua e de qualquer discurso, apesar do que emane o comentarista mais inspirado, não o será bastante profundo para explicitar-la; (LEVI-STRAUSS, 1976, p. 112).
\end{abstract}

A música viola o corpo humano. Ela o põe de pé. Os ritmos musicais suscitam os rirmos corporais. A orelha não pode se fechar quando se encontra com a música. Por ser um poder, a música se associa a todo poder. É essencialmente desigual. Ouvir e obedecer vão unidos (Obaudire). (QUIGNARD, 1998, p. 191).

Comecemos com a seguinte pergunta básica, mas essencial, para nossa reflexão: por que um determinado modo 4 musical ou determinados intervalos 5 musicais produzem efeitos consonantes e outros dissonantes? Como se sabe bem, a distinção entre consonância e dissonância está presente desde os antigos gregos em relação ao modo apolíneo (modo dórico) e ao modo dionisíaco (modo frígio)6. Porém, ela tomou diferentes significados no contexto da tonalidade, na qual a dita oposição se aplica a intervalos. Então, qual é a censura social que se encontra desde Aristóteles e que gerou tanto rechaço à música dionisíaca de então como também à música qualificada "atonal" do começo do século XX?

$\mathrm{Na}$ ampla história da música ocidental, cujo antecedente direto é geralmente localizado na Grécia Antiga, o ouvinte e a escuta experimentaram múltiplas mudanças. A lei que rege um modo de escutar não se encontra fora de determinações

3 Artigo originalmente publicado sob o título "Modos de escucha en música y en psicoanálisis" em Káñina, Rev. Artes y Letras, Univ. Costa Rica XLIII (1) (Enero-Abril) 2019:9-24/ISSN: 2215-2636. Tradução para o português do Brasil realizada por Renata Mattos Avril.

Este artigo é produto da linha de investigação "Música, psicanálise e educação" dirigida pelas Doutoras Olga Picún e Ana María Fernández Caraballo (FIC e FHCE, Udelar). Como antecedente de invenstigação, conta o artigo "Relaciones entre música y psicoanálisi: escucha y escritura de casos" de Ana María Fernández Caraballo publicado em Fermentario, 9(2), 2015, revista del Instituto de Educación, Facultad de Humanidades y Ciencias de la Educación, Universidad de la República. www.fhuce.edu.uy; Faculdade de Educação, UNICAMP, www.fe.unicamp.br; Centre d'Études sur l'Actuel et le Quotidien, Sorbonne, www.ceaq-sorbonne.org. Ver na bibliografia: Fernández Caraballo, 2015.

$4 \mathrm{Em}$ termos muito concisos, se pode dizer que um modo musical é uma sucessão de sons por graus conjuntos, os quais guardam certas relações intervalares consecutivas. Os sistemas modais foram utilizados na música grega antiga e na música medieval (modos gregorianos); são observados na música de tradição popular do Ocidente e também em culturas não europeias.

5 Denomina-se intervalo a diferença de altura ou frequência entre dois sons, sejam superpostos ou consecutivos. Os intervalos na música tonal são: uníssono, terças e sextas maiores e menores, quintas e oitavas justas; enquanto que os demais são considerados dissonantes.

6 A esse respeito, ver : Nietzsche, 1973, e também o trabalho que realiza Didier-Weill, 1999. 
históricas, políticas, sociais que excedem o campo especificamente musical. Não obstante, as transformações musicais são inevitáveis para se aproximar de uma compreensão das mudanças que se produzem no ouvinte e no ato de escutar uma obra musical. Mais ainda em contextos como o Modernismo, que, a partir de diferentes concepções estéticas, viola uma parte substancial da identidade do sistema tonal, cuja hegemonia definiu o universo simbólico ocidental durante mais de dois séculos. Ademais, não devemos deixar de apontar os inconvenientes que se revelam ao se querer expressar algo a respeito dos efeitos que a escuta de qualquer obra musical produz.

Isso talvez se deva à dificuldade específica da música, que tem a particularidade de estar distanciada da representação 7 . Recordemos as apreciações de Hegel (1991) em seu livro Estética II, no capítulo "Sobre a música", quando aponta seus traços característicos: fora de toda representação, de uma modalidade ao mesmo tempo fugitiva e negativa, se entrelaça "em" e "com" o silêncio (FERNÁNDEZ CARABALLO, 2015, p. 3).

Contudo, que lugar há tido a música e a dimensão do sonoro para a psicanálise (Freud e Lacan)s? Um dos pontos fundamentais a ressaltar é a importância da relação entre pulsão invocante e música. A esse respeito, afirma Diddier-Weill:

\begin{abstract}
A vocação de fazer-nos humanos nos é transmitida, em sua origem, por uma voz que não nos passa a palavra sem nos passar ao mesmo tempo a sua música: o infans recebe a música dessa "sonata materna" como um canto que, de entrada, transmite uma dupla vocação: escutas a continuidade musical de minhas vogais e a descontinuidade significante das minhas consoantes? (DIDIER-WEILL, 1999, p. 7)
\end{abstract}

Por sua vez, em "Ódio à música", Pascal Quignard (1998) entende que "não podemos não ouvir"; muito antes de colocar em exercício a visão, a criança é submetida a sons em que a audientia é uma obaudientia. O som nunca se emancipa totalmente de um movimento do corpo que o causa e o amplifica, é a obediência materna.

O vínculo entre a mãe e a criança e a aquisição da linguagem se formam no âmbito de uma incubação sonora. O ruído do mundo é percebido como um ronronar surdo, doce e grave sobre o qual se eleva a voz da mãe, base da melodia. O som toca instantaneamente o corpo. Diante do som, o corpo, mais

7 Sobre esta temática, ver: Fernández Caraballo, 2010.

8 Sobre esta pergunta, insistimos também em Fernández Caraballo, 2015, e em Villalba e Fernández Caraballo, 2012 
do que desnudo, está desprovido de pele. As orelhas não têm prepúcio nem pálpebras. Durante a audição, somos prisioneiros. O som é um perfurador de coberturas, já que não sabe o que é um limite, sem interno nem externo. A audição não é como a visão, que pode ser cancelada pelo uso das pálpebras, ou por um anteparo. Não há nada no sonoro que nos retorne uma imagem localizável, simétrica e invertida de nós mesmos, como o faz o espelho. $O$ eco não é exatamente um objectus, não é um reflexo jogado diante do homem: é uma reflexão sonora, e quem o ouve não se aproxima dele sem destruir seu efeito. Não há espelho sonoro de onde o emissor se contemple (QUIGNARD, 1998, p. 104).

Por outro lado, em Freud e em Lacan, o lugar que adquiriu a música e o sonoro foi altamente diverso. Indicaremos alguns exemplos para demonstrá-lo. Em $O$ "Moisés de Michelangelo", Freud (1914) salienta a atração que geravam as obras de arte: " alguém as admira, se sente subjugado por elas, mas não sabe dizer o que representam" e acrescenta que a escultura, a poesia e, em menor grau, a pintura the produzem uma "poderosa influência". Sustenta que "ela [a poderosa influência] me moveu a permanecer face a elas [as obras de arte] durante horas quando tive oportunidade, e sempre quis apreender da minha maneira, ou seja, reduzindo a conceitos, aquilo que me afetava deste modo" (Freud, 1914, p. 217).

Contudo, sobre a música, indica algo radicalmente diferente:

Quando não posso fazer isto - como me ocorre com a música, por exemplo -, sou quase incapaz de obter algum gozo. Uma disposição racionalista ou talvez analítica se se agita em mim para não me deixar comover sem saber porque assim o estou sendo e o que me comove (FREUD, 1914, p. 217).

Para Lacan, a música e a dimensão do sonoro adquirem, todavia, um lugar relevante, incluindo pontuações que recorrem grande parte de sua obra. Por exemplo, em seu Seminário "Mais, ainda", propõe que "o Barroco é a regulação da alma pela escopia corporal". Quer dizer, que se separamos a música do campo escópico, a colocamos do lado da pulsão invocante. Mais que isso, afirma que

Deveríamos falar da música à margem. Para tanto, falo somente do quanto se vê em todas as igrejas da Europa, quanto se pendura nas paredes, se desmorona, deleita, delira. O que há pouco chamei de "obscenidade", mas exaltada (LACAN, 1972-1973, p. 101).

Está fazendo referência ao fato de que a música é, também, uma maneira de tratar o vazio. 
Algo disso se encontra no Barroco em sua característica de levar ao limite o trabalho com o som em detrimento do silêncio. Trata-se do horror vacuig, o qual consiste em levar o ornamento até o extremo, o qual se mostra e se exibe, até o ponto de ser qualificado por Lacan como "obsceno" (FERNÁNDEZ CARABALLO, 2015, p. 6).

No artigo "A emancipação da dissonância. A propósito do Caso Schönberg de Esteban Buch", François Dachet (2008) aborda os efeitos subjetivos e sociais que a música pode gerar. Baseia-se no livro de Esteban Buch (2006), O caso Schönberg, que se detém a estudar de forma profunda o "escândalo que suscitou a composição atonal de Schönberg e sua relação com a Viena de Freud", além das relações entre músicos e psicanalistas. Assim, de que modo o Modernismo produz transformações na produção musical e como estas afetam a escuta?

\section{Modernismo Musical E Desafios Na Música: Schönberg E FreUd}

$\mathrm{Na}$ transição do século $\mathrm{XIX}$ ao século $\mathrm{XX}$, são produzidas importantes mudanças no pensamento artístico do Ocidente que instauram o Modernismo. A existência de uma solução de continuidade com as dinâmicas de sucessão dos diferentes estilos artísticos é o aspecto substancial desta quebra, na medida em que o Modernismo não necessariamente constitui uma reação contra o Romantismo, mas contra uma concepção de arte que havia predominado durante vários séculos. A este respeito, Arthur Danto aponta que o Modernismo

...está marcado pelo acesso a um novo nível de consciência, refletido na
pintura como um tipo de descontinuidade, como se acentuar a representação
mimética se tivera tornado menos importante que outro tipo de reflexão sobre
os sentidos e os métodos de representação (DANTO, 1999, p. 30).

A nova consciência surge de um exercício de autocrítica não apenas no âmbito das artes, como também nas ciências, na filosofia etc. (DANTO, 1999).

$\mathrm{Na}$ música, esse nível de consciência adquire sua máxima expressão na dissolução da tonalidade como sistema hierárquico de organização dos sons em estreito vínculo com o componente formal. Este sistema atravessa os diferentes

9 A expressão latina horror vacui (medo do vazio) se emprega na história da arte para descrever o preenchimento de todo espaço vazio em uma obra de arte com algum tipo de desenho ou imagem. É característico do Barroco e, especialmente, do Rococó, assim como da decoração islâmica e do luxo ostentador da arte bizantina. 
estilos que se desenvolvem no mundo ocidental desde o último quarto do século XIX. As transformações que se experimentam em cada período surgem transgredindo em alguma medida as normas que as regem, mas sem perder sua identidade. $O$ reconhecimento desta identidade associada a essas transgressões ou "desvios" segundo a denominação de Kröpfl (2006) - é o que permite ao receptor se situar em um contexto estético particular.

O sistema tonal se baseia em um conjunto de relações dialéticas, entre outras: tensão-resolução, consonância-dissonância. Cada oposição está definida por um vínculo de dependência de um dos componentes: a tensão se encontra subordinada à resolução, enquanto que a dissonância à consonância; tanto a resolução como a consonância funcionam como pontos de confluência. Dentro deste sistema, caracterizado pela direcionalidade discursiva, cada som ou grau de uma escala temperada10 maior ou menor corresponde à nota fundamental de uma tríade 11 que poderá ter, segundo uma ordem hierárquica, função de tônica, dominante (quinto grau e sétimo grau alterado ou sensível) ou de subdominante (segundo, quarto e sexto grau). Desta maneira, a tensão gerada por um acorde com função dominante implica uma resolução da tônica, como único ponto possível de repouso harmônico.

Devido à redundância deste sistema e ao vínculo harmônico-estrutural - que funciona hierarquicamente frente ao resto dos parâmetros musicais (melodia, ritmo, timbre, entre outros) -, uma escuta competente na música ocidental da época contaria com elementos referenciais suficientes tanto para se localizar na estrutura de uma obra quanto para "prever" - considerando os limites que impõe a criatividade - sua evolução e seu final. Por outro lado, o abandono da tonalidade supõe, em termos estratégicos, vulnerabilizar em alguma medida o conjunto das relações hierárquicas que a sustentam, o que exige à escuta o desenvolvimento de novas capacidades ou competências, de acordo com os diferentes modos de transcender o sistema tonal, dos quais se abordam com intenção dialógica: a música de Claude Debussy e a Segunda Escola de Viena12.

${ }_{10}$ Cuja afinação se fixa a partir de um lá de 440 Hertz.

${ }_{11}$ Acordes que se formam mediante à superposição de duas terceiras. Por exemplo: dó, mi, sol.

12 A Primeira Escola de Viena foi integrada por Mozart, Beethoven e Haydn. 
O processo de transformação começa em pelo Romantismo, quando Chopin, Liszt e Wagner13 introduzem mecanismos de expansão da tonalidade e de quebra da correspondência entre a função harmônica e as formas tradicionais. Tem um papel importante neste sentido o emprego de estratégias para retardar ou evitar o repouso, como a exacerbação do cromatismo14, os acordes sem resolução e a enarmonia, que permite mudar de contexto harmônico no percurso de uma obra; também a introdução de escalas forasteiras ao sistema tonal, a composição de peças breves ou em um único movimento que não respondem às estruturas arreigadas ao classicismo, ou a discursividade excessivamente prolongada. A combinação seletiva desses ou outros recursos que comprometem os componentes harmônicos e formais da tonalidade, a debilitando ou a rompendo, definem os diversos caminhos estéticos ou estilísticos que são empreendidos no começo do século XX, cuja sustentação ideológica se expressa em ocasiões através de manifestos, adquirindo desta maneira um caráter de movimento artístico.

Claude Debussy é, segundo Pierre Boulez, quem propõe no aspecto estrutural uma ruptura completa com a tradição. Ainda que sua estética possa ser associada fundamentalmente ao impressionismo, existe uma matriz entre o significado que a obra de Debussy tem para a história da música e o que esta corrente estética adquire para a história da arte. A aproximação estética do compositor francês com o Simbolismo literário, assim como com o decadentismo, se observa até mesmo nos referentes de parte de sua obra: "Prélude à l'après-midi d'un faune" (1892-1894) sobre um poema de Stéphane Mallarmé, a ópera "Pelléas et Mélisande" (estreia em 1902) baseada na peça teatral homônima de Maurice Maeterlinck, as canções sobre a poesia de Paul Verlaine ou de Charles Baudelaire, dentre outros. Diferentemente do que ocorre com Debussy, com relação ao Modernismo, o impressionismo pictórico é considerado um antecedente contra o que o expressionismo reage, como movimento verdadeiramente vanguardista. É reveladora desta diferenciação a correspondência

13 Não obstante, no prelúdio do oratório A criação (1798), Joseph Haydn, leva ao extremo o cromatismo e a dissonância.

14 Ver nota 19. 
que Boulez estabelece entre Debussy, Anton Webern e Mallarmé, no seguinte fragmento de seu "Incipit" ou na "Homenagem a Webern"15 (1952):

\begin{abstract}
Com efeito, somente Debussy pode aproximar-se de Webern em uma mesma tendência a destruir a organização formal preexistente na obra, em uma mesma recorrência à beleza do som por si mesmo, em uma mesma pulverização elíptica da linguagem. E se é possível afirmar - oh Mallarmé que Webern estava obcecado pela pureza formal até no silêncio, ele levou esta obsessão a um grau de tensão que, até então, a música desconhecia (BOULEZ, 1952, citado por DE ASSIS, 2012, p. 45).
\end{abstract}

Em Debussy, a construção de seções de diferentes longitudes não corresponde a uma forma pré-determinada dependente do sistema tonal, mas sim que aparece associada a mudanças de atmosfera. Essa ruptura se consolida ao combinar-se ao enfraquecimento da tonalidade, produzido mediante estratégias geradoras de ambiguidade, tais como: a construção de uma obra em planos superpostos independentes, ou seja, em âmbitos diatônicos diferentes, que pode ser escutada como politonalidade; a desfuncionalização tonal através do paralelismo de acordes ou o emprego de modos gregorianos medievais, escalas pentatônicas 16 ou escalas de tons inteiros 17; o uso de cromatismos ou do cromático entre os distintos planos, o a densificação rítmica que produz "manchas sonoras", com a consequente perda da sensação de pulso e da relação consonância-dissonância. A vulnerabilização das tensões que compartilha o uso desta estratégia atenta contra a direccionalidade discursiva do sistema tonal e é percebida como uma tendência ao estatismo.

Nos anos de 1950, o musicólogo espanhol radicado no México, Adolfo Salazar, se expressava sobre o rompimento da tensão consonância-dissonância e o estatuto que adquire a cor tímbrica da música do compositor francês:

Assim, em Debussy, o som vale por si próprio: a dissonância é um valor, como a consonância pode ser-lo, mas não uma com relação à outra; o timbre é outro valor que transcendeu a hierarquia que antes tinha a tônica e ao redor da qual se ordena toda a obra com uma lógica que escapa à análise, mas cuja sensação satisfatória se acusa na consciência (SALAZAR, 1954, citado por LABORDA, 2004, p. 11).

\footnotetext{
15 Este escrito foi publicado em várias ocasiões, sob diferentes títulos e em diversos idiomas. A versão original apareceu no New York Herald Tribune em 1952 com o título Note to tonight's concert: Weber's works analysed (De Assis, 2012, p.45).

${ }_{16}$ Os modos medievais e as escalas pentatônicas carecem de nota sensível (sétimo grau alterado). 17 A escala de tons inteiros e a escala cromática têm em comum que todos os seus intervalos consecutivos são iguais, para tanto, não se produzem hierarquias entre os sons que as formam. No primeiro caso, a distância entre dois sons é um tom, enquanto que no segundo caso é de um semitom. O intervalo de semitom se denomina cromático ou cromatismo.
} 
A Segunda Escola de Viena, encabeçada por Arnold Schönberg e seus discípulos Anton Webern e Alban Berg, propõe outro dos múltiplos caminhos estéticos do modernismo musical, parte dele associado ao expressionismo alemão. Desenvolvido em seus começos por dois coletivos de artistas plásticos, Die Brücke A Ponte - (DRESDE, 1905-1913) e Der Blaue Reiter - O Cavaleiro Azul - (BERLIM, 1911-1914), o expressionismo não aspira a representar a realidade, mas sim a percepção que desta tem o artista.

O processo criativo de Schönberg, que culmina no rigor do serialismo o método dedocafônico, surge ao se levar ao extremo os princípios do Romantismo. A partir de uma perspectiva pós-traumática, caracterizada por uma discursividade prolongada cujo referente é Gustav Mahler -, Schönberg se foca em explorar a tonalidade até as últimas consequências, definindo entre 1909 e 1916 sua etapa atonal livre 18, que constitui o gérmen do serialismo dodecafônico.

Nele [Schönberg], o momento subversivo propriamente falando é a mudança
de função da expressão musical. Já não se fingem paixões, mas por meio da
música se registram emoções indiscutivelmente corpóreas do inconsciente,
shocks, traumas. Atacam as tábuas da forma porque estas submetem tais
emoções à sua censura, as racionalizam e as transpõem em imagens. As
inovações formais de Schönberg estavam relacionadas com a modificação
do conteúdo da expressão. Servem à irrupção da realidade desta. As
primeiras obras atonais são protocolos, no sentido dos protocolos oníricos da
psicanálise (ADORNO, 2003, p. 43).

A mudança "subversiva" de Schönberg, quanto à expressão musical, estabelece uma diferença importante com a música de Debussy. As atmosferas dos prelúdios para piano (1909-1913) são uma mostra de como o compositor francês põe em contato o ouvinte com o sensorial ou o sensível, o que justifica sua habitual associação ao impressionismo.

Como sinaliza Adorno em outro de seus escritos a respeito da relação da continuidade da etapa atonal e da etapa serial, os novos princípios "levam à autoconsciência o que já se encontrava latente na emancipação da música a respeito dos limites dos sistemas de referência tradicionais" (ADORNO, 2006, p. 70). $\mathrm{Na}$ Segunda Escola de Viena, a atonalidade surge da eliminação de hierarquias, através de uma constante circulação do tonal cromático; a emancipação discursiva da

${ }_{18}$ Schönberg preferia o termo "politonal".

Psicanálise \& Barroco em revista | v.17, n. 3 | dezembro de 2019 
dissonância, que iguala a função consonância-dissonância; e o uso intenso de dissonâncias duras (segunda menor ou sétima maior), dentro de uma rítmica atonal ou com acentos deslocados. A coerência em uma obra está dada fundamentalmente pela presença de elementos aglutinadores, como a recorrência a alturas e intervalos fixos.

Neste contexto, a exploração da variável tímbrica, que põe em jogo a tradicional hierarquia do parâmetro da altura, incide em novas técnicas de execução dos instrumentos e da emissão vocal, como canto falado (sprechgesang). Mesmo assim, incide na introdução da melodia de timbres (klangfarvenmelodie), cujo antecedente é possível de ser encontrado no princípio de "divisão da melodia" empregado por Wagner, no qual uma linha melódica está instrumentada de tal maneira que os sons que a formam se descompõem em timbres sucessivos (ADORNO, 2006). Dito com outras palavras, se trata da distribuição dos sons de uma melodia entre vários instrumentos, utilizando sobretudo o desaparecimento mais do que a fissura. Todos estes recursos são também utilizados por Webern e Berg em suas etapas atonal.

A composição mediante o método dodecafônico parte da criação de uma série que envolve os doze sons da escala cromática. Esta série constitui o material sonoro de uma peça e funciona sob a regra de que os sons devem ser utilizados - horizontal (melodias) ou verticalmente (sons superpostos ou acordes) - com rigor, de acordo com uma ordem pré-estabelecida, evitando o surgimento de um centro tonal por recorrência. Desta forma, se produz a emancipação dos sons individuais a respeito do seu acordo, em termos da tonalidade (ADORNO, 2006). Ao longo de uma obra, a série pode ser manejada utilizando procedimentos contrapontísticos, como retrogradação, inversão interválica ou inversão retrogradada; também pode ser dividida em grupos ou transportada, o que significa manter os mesmos intervalos melódicos entre os sons da série original em seu novo âmbito diatônico. No serialismo dodecafônico, segundo Adorno (2006), derivado do princípio dialético da variação, convergem o uso do tonal cromático e a ordem rigoroso, de maneira que as relações hierárquicas dos sons ou graus de uma escala são eliminados por completo.

À diferença de Webern - que se radicaliza por propor uma destruição progressiva da herança romântica tendendo a "reabilitar o poder do som" (BOULEZ, 1952), o que inclui a sublimação do despojo de toda retórica redundante -, Schönberg se orienta mais em direção da descomposição da ordem tonal. Por esse motivo, 
Webern se converte no principal referente da Nova Música, durante a segunda pósguerra. Neste novo contexto, o método serial criado por Schönberg se radicaliza nas mãos da chamada Escola de Darmstadt (integrada por Boulez, Luigi Nono e Karlheinz Stockhausen, dentre outros) ao tornar-se extensivo a todos os parâmetros musicais, sob o nome de serialismo integral.

Os diferentes universos estéticos ou estilísticos que se concentram na mudança de século, sem alguma dúvida, colocaram o ouvinte a uma nova realidade. A tonalidade tinha se encarregado de preservar ao longo de vários séculos uma identidade musical que manteve o ouvinte num espaço de conforto. As vanguardas modernistas o obrigaram a sair deste lugar e a estabelecer de forma conflitual um vínculo com a nova música, assim como a sensibilizar-se face aos múltiplos desafios sonoros que surgiram durante o século XX, em pleno diálogo com o passado.

Finalmente, resta abordar a seguinte pergunta: que vínculos podem ser vislumbrados entre as mudanças nas composições de Schönberg no início do século passado em Viena e a psicanálise que estava criando Sigmund Freud? Ainda, que mudanças se produzem na escuta a partir de Schönberg e Freud ${ }_{19}$ ? No trabalho acima citado, François Dachet (2008) estuda em profundidade a forma pela qual se sucedem as inovações na escuta a partir de Freud e de Schönberg. Minimamente, destacaremos dois aspectos em comum: ambos viveram em Viena no mesmo tempo e caso é uma palavra compartilhada entre "caso Schönberg" e os "casos freudianos".

De um lado, a expressão "o caso Schönberg" se produz pela apresentação de sucessivos concertos em que uma das suas obras fora interpretada. Mais que isso, ao longo dos anos, os argumentos estéticos que vieram a posteriori justificar as manifestações ruidosas durante os concertos se deslocam e se transformam.

\footnotetext{
Sob o refúgio dos julgamentos dos críticos decola isso que será estabelecido como o limite subjetivo em torno do qual gira, até mesmo hoje, a apreciação da música contemporânea: trata-se de música? Não se trata somente de "gosto", mas sim do limite subjetivo que levará a produzir o julgamento que sinalizará a diferença entre a "estranheza" à qual se submete a escuta de uma criação musical contemporânea e a "sensibilidade" que ela supõe. Os julgamentos incluíram inclusive a referência às normas admitidas da música da época que permaneceram como o eixo de comparação: harmonias originais, por vezes bizarras, atmosfera estranha e sonoridade encantadora,
}

19 Sobre esta pergunta, nos detivemos em: Fernández Caraballo, 2015. 
um tanto descuidado, um toque literário, cuidadoso até o pedantismo etc. (DACHET, 2008, p. 12)20.

Inclusive, não se trata de novidades musicais o que produziu a atenção do público, "é a quantidade de dissonâncias": "Atentado maldoso contra as orelhas", "anarquia completa", "terrorismo", estas eram as qualificações que recebiam a obra por parte da crítica (Dachet, 2008, p. 12). Nas palavras de Buch (2006), "a crítica estética torna-se então uma crítica moral".

O discurso muda de orientação: é a exterioridade à música reconhecida e aceita o que está sublinhado. Os documentos apresentados por Buch permitem abordar como se construiu em sua época uma "natureza da música" para colocar em comparação aquilo que não aparece na dita natureza. O que se repreende a Schönberg é o rechaço da tonalidade (FERNÁNDEZ CARABALLO, 2015, p. 9).

...a ideia de que, ao longo do século $X X$ e ainda hoje, permanecerá sendo o argumento favorito dos inimigos do vanguardismo musical, a saber, que toda música não tonal é contrária às leis da natureza $(\mathrm{BUCH}, 2006$, p. 210).

A respeito, interroga Dachet (2008): qual é o efeito da denominação "atonal"?, ao que responde:

Ela não apenas apoia a apreciação já citada do crítico segundo a qual a música de Schönberg é contrária à natureza, mas ainda põe a escuta do público em um turbilhão em cujo interior não é possível liberar os princípios da composição musical colocadas em jogo por Schönberg, sua singularidade (DACHET, 2008, p. 18).

As composições de Schönberg baseadas no período atonal livre o levaram a um beco sem saída, dado que requeria novos catálogos de material e de regras para cada obra.

Após numerosas tentativas, escreveu a um de seus discípulos em julho de 1921: "Hoje fiz uma descoberta que assegurará a supremacia da música alemã durante os próximos cem anos". Nesta data, se iniciou seu método de composição dodecafônico através do qual Schönberg acreditou ser capaz de propor uma estrutura interna teórica para cada obra (FERNÁNDEZ CARABALLO, 2015, p. 11).

20 As traduções do texto de Dachet, do francês para o espanhol, são de Ana María Fernández Caraballo. 
As ideias sobre 0 atonalismo que se sucederam a respeito de Schöngerg podem ser relacionadas com outro futurismo, o futurismo russo e suas regras poéticas (Dachet, 2008), similares aos princípios de escrita de Schönberg.

O que se encontra exposto na poética de Roman Jakobson: essa projeção do eixo da metáfora sobre os da metonímia, paralelos à equivalência sustentada por Schönberg da harmonia e da melodia. No tempo em que era criada a expressão "música atonal", a crítica da época não havia ignorado completamente esta visão. "Simultânea e melódica", escreveu Siegmund Piesling a propósito do Pierrot Lunaire em 1912 nas colunas do National Zeitung (FERNÁNDEZ CARABALLO, 2015, p. 11).

Por outro lado, como aponta Dachet (2008), o artista não apenas antecipa o psicanalista como coloca a crítica em dificuldades: "Porém, o que não está mais na "música de Schönberg" pode estar dentro do que será chamado de "o envoltório" do caso Schönberg. Sob a condição se lembrar que, a respeito de Freud, o que se chama ordinariamente de caso é essencialmente a escrita daquilo que não encontrou direção nas formas de transferência ao longo das sessões e que Freud devolve com um ato de escrita" (DACHET, 2008, p. 14). 


\section{REFERÊNCIAS:}

ADORNO, Th. Filosofía de la nueva música. Madrid: Akal, 2003.

ADORNO, Th. Escritos musicales I-III. Madrid: Akal, 2006.

BUCH, E. Le cas Schönberg. Paris: Gallimard, 2006.

CARABALLO, A. M. F. Relaciones entre música y psicoanálisis: escucha y escritura de casos.

En Fermentario, 9(2), diciembre de 2015, pp. 1-13, 2015. ISNN 16886151

http://www.fermentario.fhuce.edu.uy

CARABALLO, A. M. F. La música al margen o fuera de la representación: entre lo audible y lo legible. En Memorias del 6.to Foro Latinoamericano Memoria e Identidad. Asociación Civil Signo, Unesco, Universidad de la Rioja. Montevideo, 2010.

DACHET, F. L'émancipation de la dissonance. A propos du Cas Schönberg d'Esteban Buch. In: Superflux, 2, mars, Paris: Éditions de l’Unebévue, 2008.

DANTO, A. Después del fin del arte. El arte contemporáneo y el linde con la historia.

Barcelona: Paidós, 1999.

DE ASSIS, P. (Coord.). Pierre Boulez. Escritos seletos. Lisboa: Casa da Música, Centro de Estudos de Sociologia y Estética Musical, 2012.

DIDIER-WEILL, A. Invocaciones. Dionisio, Moisés, San Pablo y Freud. Buenos Aires: Nueva Visión, 1999.

FREUD, S. (1914). El Moisés de Miguel Ángel. Tomo XIII. En Sigmund Freud. Obras completas. Buenos Aires: Amorrortu Editores, 1997.

HEGEL, G.W.F. Estética II. Barcelona: Península, 1991.

KRÖPFL, F. Algunas reflexiones en torno a la música. En Revista de Filosofía, 20, agosto.

Córdoba: Universidad Nacional de Córdoba, 2006.

LABORDA, J. G. La música moderna y contemporánea a través de los escritos de sus protagonistas: una antología de textos comentados. Sevilla: Doble J, 2004.

LACAN, J. (1972-1973). El Seminario, Libro 20: Aun. Buenos Aires: Paidós, 1998.

LEVI-STRAUSS, C. El hombre desnudo. Mitológicas IV. México: Siglo XXI, 1976.

NIETZSCHE, F. El nacimiento de la tragedia, o Grecia y el pesimismo. Madrid: Alianza

Editorial, 1973.

QUIGNARD, P. El odio a la música. Diez pequeños tratados. Madrid: Andrés Bello, 1998. 
VILLALBA, A. y Fernández Caraballo, A. M. Con-dissonâncias: ato analítico, poesia y música. EN LEITE, N. y Milán-Ramos, J. G. (Eds.) EntreAto: o poético e o analítico. Campinas: Mercado de Letras, 2012, pp. 321-338. 


\title{
Consonance And Dissonance In Music Listening Modes And In Psychoanalysis
}

\begin{abstract}
In the long history of Western music, whose direct antecedent is usually located in ancient Greece, the listener and the listening have experienced multiple changes. Historical determinants, social and political, that exceed the specifically musical field, underlie the way of listening. However, the musical transformations are inescapable to approach an understanding of the changes that occur in the listener and in the act of hearing a musical work. In this work a series of questions guide the analysis and reflections. How are the sound transformations in modernism produced and how do they affect listening? What place has music and the dimension of sound for psychoanalysis (Freud and Lacan)? And, what relationships can be established between these transformations and psychoanalysis?
\end{abstract}

KeY WoRDS: Consonance; Dissonance; Music; Psychoanalysis. 


\section{Consonances Et Dissonances Dans Les Modes D’ecoute En Musique Et En Psychanalyse}

\section{RÉSUMÉ}

Dans la longue histoire de la musique occidentale, dont l'antécédent direct est souvent situé en Grèce Antique, l'auditeur et l'écoute ont subi de multiples changements. La loi qui régit un mode d'écoute ne se trouve pas au-delà de déterminations historiques, politiques, sociales, qui excèdent le champ spécifiquement musical. Cependant, les transformations musicales s'avèrent incontournables pour se rapprocher d'une compréhension des changements qui se produisent dans l'auditeur et dans l'acte d'entendre une pièce musicale. De quelle manière la musique a-t-elle été traitée par Freud et par Lacan? Quel est l'intérêt que les dimensions sonores, dans leurs différents traitements, peuvent susciter pour la psychanalyse? Sur quel mode se produisent les transformations sonores dans le modernisme et comment affectentelles l'écoute? Quelles relations peuvent être établies entre ces transformations et la psychanalyse?

MoTS-CLÉS : Consonances; Dissonances; Musique; Psychanalyse. 
Consonâncias E Dissonâncias Nos Modos De Escuta Na Música E Na Psicanálise

RECEBIDO EM 24-09-2019

APROVADO EM 10-10-2019

(C) 2019 Psicanálise \& Barroco em revista

http://www.seer.unirio.br/index.php/psicanalise-barroco/index

revista@psicanaliseebarroco.pro.br

Programa de Pós-Graduação em Memória Social — UNIRIO

Memória, Subjetividade e Criação

www.memoriasocial.pro.br/proposta-area.php 